\title{
TRANSGRESSÃO NA CULTURA JURÍDICA: uma leitura de Günther Jakobs
}

\author{
Emanuele Abreu Rodrigues ${ }^{1}$
}

\begin{abstract}
RESUMO: O objetivo deste artigo é analisarmos os ensinamentos de Günther Jakobs a partir de uma leitura da obra "Sociedade, Norma e Pessoa". O autor faz a elaboração de uma teoria de Direito Penal pressupondo uma reconstrução de uma linguagem para o Direito Penal por meio de novos conceitos, procurando reformular os fundamentos do Direito Penal. Primeiramente, veremos a forma como Jakobs concebe uma nova Teoria Normativa. A seguir, apontaremos alguns aspectos de sua proposta.
\end{abstract}

PALAVRAS-CHAVE: Norma. Teoria Normativa. Günther Jakobs.

\section{LEGAL CULTURE IN BREACH: a reading of Günther Jakobs}

\begin{abstract}
The objective of this paper is to analyze the teachings of the Günther Jakobs from a reading of the book "Society, and Person Standard." The author makes the development of a theory of criminal law presupposes a reconstruction of one language to the Criminal Law through new concepts, looking for reshape the fundamentals of criminal law. First, we will see how Jakobs conceived as a new normative theory. Next, identify some aspects of its proposal.
\end{abstract}

KEY-WORDS: Standard. Normative theory. Günther Jakobs.

\section{1 - CONSIDERAÇÕES INICIAIS}

Vislumbramos que a estrutura normativa do direito penal clássico mostra-se insuficiente, visto que, vivemos numa sociedade complexa em que o risco está em todos os lugares e é necessário inserir o Direito Penal na epistemologia da incerteza e do risco, fazendo-se imprescindível sua análise por um viés interdisciplinar.

A partir desses pressupostos que circunscrevem o estudo dos fundamentos do Direito Penal, utilizaremos como rumo limitador a analise da perspectiva proposta por Günther Jakobs amparada na matriz sistêmica. Neste artigo esboçaremos a Teoria Normativa de Jakobs a partir de uma reflexão das obras "Sociedade, Norma e Pessoa", "Ciência do Direito e ciência do Direto Penal", "Uma Teoria da Obrigação Jurídica” e "Fundamentos de Direito Penal”.

A importância do autor vem de sua 'elaboração da teoria do Direito Penal que pressupõe uma reconstrução de uma linguagem para o Direito Penal por meio de

\footnotetext{
1 Advogada. Mestre em Filosofia pela UFSM. Especialista em Direito Processual pela FADISMA. Email: somanu_rod@hotmail.com
} 
novos conceitos, mas também de novas expressões que representam adequadamente esses novos conceitos' (Jakobs, 2003-A, p. VIII e IX).

Jakobs é um dos mais categorizados penalistas da atualidade, brindando a comunidade jurídica com um rico e original pensamento sobre a doutrina finalista da ação, e defende a necessidade de se descobrir uma nova visão para o direito penal, a partir da renormatização dos conceitos jurídico-penais, voltando-os à função que corresponde ao direito penal.

Para tanto, Jakobs (2003-D, p. 8) revê conceitos aparentemente sedimentados como o da culpabilidade, o da ação e do bem jurídico, bem como a necessidade de proteção da norma. Porém, nossas pretensões são mais modestas, examinaremos como se forma a 'Nova Teoria Normativa' que 'compreende o delito como um fenômeno social'.

\section{2 - O DIREITO PENAL COMO PARTE DA SOCIEDADE}

O direito penal como parte da sociedade resulta na tarefa de compreender e interpretar os fenômenos jurídicos, como fenômenos complexos. Todavia, isto só é possível partindo-se de uma teoria pragmática que consiga um alto nível de abstração para dar conta da complexidade do sistema social.

Num primeiro momento da elaboração teórica de Jakobs, ele utiliza o projeto epistemológico de Luhmann que consiste em uma proposta antirreducionista e leva em conta o indeterminismo dos fenômenos sociais complexos.

Luhmann passa, assim, a definir a sociedade como a teoria das condições de auto-referência dos sistemas sociais. Neste sentido, a sociedade comunica em si mesma, sobre si mesma e sobre o ambiente, e somente por isso ela pode reduzir complexidade para depois produzir outras possibilidades de sentido e assim mais complexidade (QUEIROZ apud LUHMANN, 1994). A auto-reprodução da operação fundamental do sistema social que é circular e recursiva garante a continuidade do sistema social e, por isso, sua constante recorrência evolutiva.

Essa nova concepção de sociedade remete a novas formulações e significações dos acontecimentos sociais. Desta maneira, asseverou Queiroz,

uma das principais contribuições de Luhmann para a teoria e sociologia do direito está justamente na colocação do direito num lugar diferenciado do acontecer social: o direito não é um dado a priori do comportamento humano ou da regulação da convivência humana que garante a sociedade. Ele é antes uma aquisição evolutiva do sistema da sociedade, e por isso pôde 
se diferenciar de seu ambiente, formando um sistema operativo fechado, capaz de produzir seus próprios elementos constitutivos e dar conta da sua complexidade (QUEIROZ, 2003, p. 79).

Esta proposta de Luhmann é uma nova saída às questões da teorética do direito, justamente porque pode contribuir para uma teoria estrutural e funcional do direito.

Neste sentido, o direito como produção de normatização social tem, portanto, uma estrutura comunicativa. Desse modo, o social engendra complexidade, que constitui "a totalidade das possibilidades de experiências ou ações, cuja ativação permita o estabelecimento de uma relação de sentido" (LUHMANN, 1983, p.12). A produção de expectativa reduz a complexidade, ao mesmo tempo em que produz outras possibilidades de sentido. $\mathrm{O}$ direito neste contexto tem um papel fundamental de normatizar e muitas vezes normalizar expectativas, através do dever-ser e da institucionalização dos modos de normatização. Isto é possível através do que Luhmann chama de generalizações congruentes de expectativas, afirmando que

... o direito é imprescritível enquanto estrutura, porque sem a generalização congruente de expectativas comportamentais normativas os homens não podem orientar-se entre si, não podem esperar suas expectativas. E essa estrutura tem que ser institucionalizada ao nível da própria sociedade, pois só aqui podem ser criadas aquelas instâncias que domesticam o ambiente para outros sistemas sociais. Ela se modifica, portanto, com a evolução da complexidade social. (LUHMANN, 1983, p.170)

Está nova concepção do papel do direito na sociedade tem como ponto de partida a idéia de que o direito reflete um modo peculiar do agir social. Deste recorte, o direito reflete, então, de modo mais explicito o grande problema de todos os sistemas sociais: o de como manter a sua ordem interna e sua autoconservação e, ao mesmo tempo, significar ou dar sentido às "influências" do meio. Para explicar isso Luhmann rompe com concepções ontológicas, apriorísticas e objetivistas do funcionalismo clássico e passa a conceber os sistemas sociais como sistemas de interação e de comunicação.

Daí infere-se uma nova concepção de normatividade que, segundo Luhmann (1983), não se coloca mais no plano do ser e do dever-ser: o núcleo conceitual do sistema jurídico se resume a uma única diferenciação: lícito/ilícito ou legal/ilegal. Assim, o direito produz expectativas e reduz complexidade. As expectativas 
produzidas pelo sistema jurídico são as institucionalizações de comportamentos sociais, generalizáveis pela norma jurídica.

Jakobs (2003-A, p. 04), ao seu turno, afirma que o Direito Penal confirma a identidade social. Para ele "o delito não é tomado como princípio de uma evolução nem tampouco como evento que deva solucionar-se de modo cognitivo, mas como falha de comunicação, sendo imputada essa falha ao autor como culpa sua". Assim, 'a sociedade mantém as normas e se nega a conceber-se a si mesma de outro modo. Nessa concepção, a pena não é tão somente um meio para manter a identidade social, mas já constitui essa própria manutenção’.

Jakobs (2003-A, p. 07) busca enfocar, "que seja como for, a solução de um problema social por meio do Direito Penal tem lugar em todo caso por meio do sistema jurídico enquanto sistema social parcial, e isso significa que tem lugar dentro da sociedade. Portanto, é impossível separar o Direito Penal da sociedade". Aduz ainda que

existe uma dependência recíproca entre a sociedade e o Direito Penal: cabe pedir ao Direito Penal que realize esforços para assumir novos problemas sociais, até que o sistema jurídico alcance uma complexidade adequada com referência ao sistema social, do mesmo modo que inversamente o Direito Penal pode recordar a sociedade que deve ter em conta certas máximas que se consideram indisponíveis. Por isso deve ser compatível com as condições da evolução. Nem o sistema social nem o sistema jurídico saltam por cima de sua própria sombra (JAKOBS, 2003-A, p. 9).

Lynett (2005) percebeu que o direito na concepção de Luhmann é uma estrutura através da qual se facilita a orientação social, e a norma, uma generalização de expectativas. A configuração fundamental da sociedade se produz através do direito, e a missão do Direito Penal é garantir essa configuração.

Desta forma para Lynett (2005, p. 13) "na teoria dos sistemas, as sociedades modernas se caracterizam por sua complexidade, porque se trata de um mundo onde tudo é possível, onde tudo pode ocorrer. Precisamente, para facilitar a orientação do homem no mundo devem-se criar mecanismos que permitam a redução de complexidade, e um deles é a criação de sistemas sociais, dentro dos quais o direito marca os limites da configuração que se dá a si mesmo a sociedade e que a caracteriza de uma determinada maneira". Ressaltando que, "nesta tarefa de redução da complexidade, há uma estrutura muito importante que é a expectativa'.

Como argumento final, Lynett (2005, p. 14) preleciona que é "através da generalização temporal das expectativas, o sistema social cria certos mecanismos para que os cidadãos possam seguir confiando nelas apesar de sua defraudação". 


\section{- Subjetividade medida pelo social}

Houve tempo em que acreditávamos ser a lei uma fórmula "mágica", expressão definitiva do direito, através do qual o Estado poderia resolver todos os problemas jurídicos da sociedade. Acreditava-se que através da regra positiva poder-se-ia dirimir todas as hipóteses de litígios surgidos na sociedade.

O homem se organiza de forma distinta por ser dotado de inteligência. Está sempre procurando desenvolver melhor suas condições de vida e progredir. Sua vida social não esta organizada de modo inexorável e rígido; ao contrário, se desenvolve dentro de margens mais amplas, em uma grande variedade de formas suscetíveis de desenvolvimento, que exigem, sem sombra de dúvidas, um ordenamento construído sempre com liberdade. Porém, o ordenamento é fixo, rígido e constante, já a vida social do homem segue caminhos flexíveis, mutáveis, sempre em desenvolvimento.

Boaventura afirma,

melhor que ninguém, Foucault analisou o processo histórico do desenvolvimento da cidadania em detrimento do da subjetividade, para nos permitir a conclusão de que cidadania sem subjetividade conduz à normalização, ou seja, à forma moderna de dominação cuja eficácia reside na identificação dos sujeitos com os poderes-saberes que neles (mais do que sobre eles) são exercidos. Trata-se de um processo totalizador de que as ciências humanas são peça central e que opera por fraccionamentos da subjetividade (na família, na escola, no hospital, nas profissões, na prisão) para depois ser reconstituída, com base neles, a unidade do indivíduo identificado com as exigências da dominação disciplinar, as quais, por isso, nada impõem (BOAVENTURA, 1999, p. 246).

Como articulava o próprio Warat, temos a 'possibilidade de criar um novo eixo emancipatório'. Complementa,

Nós, juristas, temos que começar a rechaçar a tentação do eterno. Nossa única chance de seguir refletindo sobre o Direito sem fuçarmos estancados em nosso próprio passado, em nossos consolos secretos, como diria Borges. Com todo tempo estancado, o tempo do Direito é sempre negação da realidade, expressão de um pessimismo diante da história. A harmonia do tempo dando ilusão de segurança (WARAT, 2004, p.469).

A seu turno, Jakobs (2003-B) enfatiza que a simples orientação das normas penais por escrito, não é suficiente para fixarem o resultado desejado de uma ação. Neste sentido, “o sujeito deve entrar em sociedade para poder 
delimitar-se e compreender-se como sujeito, pois uma subjetividade isolada é tão imaginável quanto outras coisas isoladas". Assim, "a subjetividade não só é um pressuposto, mas também uma conseqüência da socialidade". Nesta maneira "o sujeito deve alcançar esse conhecimento laboriosamente e por si mesmo, do contrário, a juridicidade e para ele uma mera coerção".

\section{3 - O FUNCIONALISMO SISTÊMICO DE JAKOBS}

Atualmente, a doutrina resgata antigos postulados filosóficos científicos reproduzidos por pensadores alemães, o que está oferecendo um novo rumo para a dogmática penal, como por exemplo, os postulados sistêmicos-socias de imputação para Jakobs.

Segundo Breier (2003, p. 85), tais posicionamentos estão a oferecer um novo rumo metodológico, distinto dos postulados exclusivamente ontológicos. O objetivo vem a ser o de aproximar e redefinir os institutos do Direito Penal com as novas questões da sociedade moderna.

Ressalta o autor que a "crítica central do funcionalismo em suas diversas concepções centraliza-se no sentido de que a dogmática penal, com as construções científicas anteriores, ficou privada do contato com a realidade social, posto que as teorias estivessem centralizadas em determinados valores específicos que delimitavam a fundamentação do sistema penal" (Breier, 2003, p. 98).

A substituição destes critérios por novos princípios oportunizou para o Direito penal uma readaptação de seus postulados científicos, os quais novamente buscavam objetivar um novo parâmetro de limite para o poder punitivo do sistema penal. Jakobs fundamentou sua concepção em orientações filosóficas provenientes da Sociologia e Psicologia.

Assim, Jakobs iniciou o processo de renormatização da dogmática penal pelo raciocínio de que, se a sociedade é um organismo complexo e dinâmico, há de se realizar um esforço do direito penal para manter em funcionamento esta estrutura básica. Deste recorte, o funcionalismo sistêmico para Jakobs,

fundamenta-se através de expectativas de relacionamento, sendo que a norma exerce um fator de estabilização na relação sistema-entorno. Contrário ao funcionalismo estrutural (Roxin), o estratégico (sistêmico) não tem uma razão rígida, pois a norma origina-se por uma flexibilidade em seu sentido estrutural, onde o sistema não está fixado pela orientação da 
consciência humana, mas sim em sistemas reais expressados pelos fenômenos sociais (JAKOBS, 2003-B, p. 88).

Portanto, "a renormatização dos conteúdos do Direito penal vem a ser o ponto principal de sua nova metodologia, o que anteriormente delimitava-se por referencias pré-jurídicas, passou a ser regida por valores de reação normativopenal" (JAKOBS, 2003-B, p. 95).

Examina Breier, que a norma fundamental, expressa pela concepção Kelsiana, deixa de alcançar seus objetivos na sua criação e denominação própria. Em vez dos termos mandatos e desobediência vamos falar em validez e frustração de expectativas. Fora deste contexto o que for considerado antinormativo, com base e regras meramente normativas, distantes do acontecer social, não possuem relevância sistêmica.

O delito não pode ser mais visto como mera infração á norma de natureza pessoal (singularidade), e sim, como um fenômeno de relações sociais. Segundo Jakobs (2003-A, p. 22) aqui se encontra a amplitude de que o Direito penal tem que reestruturar "cabe rogar ao Direito penal que realize esforços para assumir novos problemas sociais, até que o sistema jurídico alcance uma complexidade adequada com referencia ao sistema social".

Neste contexto para Breier (2003, p. 96), "o delito é algo cientificamente de maior complexidade, sendo que a teoria do delito com fundamentos abstratos limitase em vários aspectos contextuais, o que impede a formação da norma".

$\mathrm{O}$ ponto central está delimitado pela sociedade e seus indivíduos. $\mathrm{O}$ objetivo de proteção penal não pode continuar delimitado apenas por bens jurídicos, mas sim pela função desempenhada pelas normas penais. O delito, na concepção de Jakobs (2003-A, p. 97), “identifica-se pela quebra de expectativas normativa, sendo convencionado por atos comunicativos, os quais atentariam contra a segurança da sociedade". O que Jakobs (2003-A, p. 97) procura evidenciar é “a reconstrução conceitual das categorias da dogmática penal a partir da nova concepção de fim do Direito Penal: a idéia de Direito Penal com relação direta a finalidade da norma".

Nesse passo Breier (2003 apud FEIJOO SÁNCHEZ, 1995, p. 59) destaca que as normas penais visam garantir a estabilidade do próprio Direito "se as pessoas estiverem convencidas que o melhor respeitar as normas, não seria preciso o Direito Penal para estabilizar os deveres".

A proposição elaborada por Jakobs, não incrimina condutas que desarmoniam o sistema social e sua operacionalidade (lesividade social) na ótica dos processos 
naturalísticos ou individuais (valores pré-jurídicos isolados), mas sim os comportamentos que contradizem com o modelo definido pela norma.

\section{4 - TEORIA NORMATIVISTA}

O normativismo, como fruto do pensamento da Escola Positiva pretendeu fulca na norma uma referência a um só tempo de cientificidade para o Direito e de limitação para a interferência no controle social exercido pelo Estado. Sendo a pedra angular do normativismo, sem qualquer sombra de dúvida, a obra de Kelsen. Entretanto para Jakobs (2003-C, p. 38), “o direito positivo leva amplamente em consideração os defeitos cognitivos, inclusive aqueles que se referem ao conhecimento das normas, no âmbito do defeito volitivo limita-se a tomar em conta alguns casos rigidamente tipificados".

Conquanto, podemos verificar que existe uma profunda separação cognoscitiva entre Dogmática Penal e realidade social estabelecendo uma relação entre seu déficit de segurança jurídica e seu déficit epistemológico-cognoscitivo. Neste viés, para não se limitar apenas nos casos típicos, o autor chega à conclusão "que criam responsabilidades todas aquelas razões de conflitos atuais que não podem se imputar a outra pessoa que o autor, sem perturbar a vigência da norma" (JAKOBS, 2003-C, p. 40).

Cabe ressaltar que para Jakobs que a vigência da norma é como o bem jurídico penal e o doutrinador reformula seu conceito dizendo que, o que protege $o$ Direito penal são os mecanismos que permitem manter a identidade de uma sociedade, é dizer, as expectativas fundamentais para sua constituição (LYNETT, 2005, p. 15). Ou seja, o bem jurídico não é o dano naturalmente perceptível, mas sim um conceito normativo: a vigência da norma. Se a sociedade se estrutura através de normas, entendidas como "esquema simbólicos de orientação" e através das quais uma sociedade assinala os aspectos fundamentais de sua configuração, o relevante não é uma lesão externa de uma situação valiosa, mas o significado da conduta: com seu comportamento o infrator expressa (comunica) que para ele não vigem as expectativas fundamentais, senão sua própria concepção de mundo.

Lynett (2005, p. 17) observar que "o eixo central deixa de ser o poder comporta-se conforme a norma, e o constitui o dever fazê-lo, que é uma perspectiva distinta".

Neste sentido, para Jakobs, a vida em sociedade, com todas as suas interações, se desenvolve com base em expectativas, e as normas são "estruturas sociais transmitidas por comunicação". A comunicação é um instrumento básico da 
interação, no qual conta não somente a perspectiva de quem atua, mas também a dos demais membros da sociedade. Este sistema de Jakobs concebe a ação como um ato comunicamente relevante.

Como se vê, "a elaboração do conceito de ação com base na comunicação implica que é relevante o esquema social de interpretação do ocorrido, porque, se as normas são 'estruturas reflexivas de expectativas', a relação de comunicação sempre se define pelo contexto" (LYNETT, 2005, p. 19).

Por fim, Breier (2003, p. 99 e 100) argui que "Jakobs considera a ação como um processo de natureza social e causal, acrescendo a ela o critério de evitabilidade como condição individual que pertence ao comportamento, não em seu aspecto material de resultado e sim sobre o ato de infringir a norma".

Assim para Jakobs, o Direito Penal não tem por função principal ou exclusiva a defesa de bens jurídicos, pois não reprime primeiramente lesões de interesses, mas o comportamento como manifestação de uma atitude de infidelidade ao Direito. Daí resulta que a violação da norma é socialmente disfuncional não tanto porque resultam lesionados determinados interesses ou bens jurídicos, mas porque a norma mesma é posta em discussão como orientação da ação e é afetada, em consequiência, a confiança institucional dos consorciados (BARATTA, 1985).

Neste sentido, Cancio Meliá (2005, p. 93) adverte para 'os fenômenos de neocriminalização, sob os quais tem se afirmado que cumpre tão-somente efeitos "simbólicos"”. A esse respeito, cumpre ressaltar, que não podemos permitir apenas um Direito penal simbólico, porque a tese central é que 'o crime não é uma realidade preexistente, mas que se cria num processo de "interação simbólica" atribui-se socialmente a qualidade de crime'. Ademais para Cancio Meliá (2005, p. 99) “parece que o preceito prefere criar ou proteger certo 'clima' ideológico do que antecipar a barreira de punição de fatos futuros, especialmente na modalidade de provocação ao ódio, pois é evidente que não é mediante a tipificação penal que se consegue este objetivo".

Deste recorte, observamos que a dogmática penal proposta por Jakobs é manter a 'vigência da norma', e não a norma positivada. Todavia está não é uma proposta abolicionista. A ausência de controle jurídico não implica necessariamente a ausência de controle social, senão sua substituição por outras formas de controle. Aliás, é justamente no termo médio da polaridade entre a norma estática e intocável e a revolução dos parâmetros anarquista que reside à idéia de permanente revisão dos cânones normativos.

\section{5 - LEGITIMIDADE E (AUTO)LEGITIMAÇÃO}


"A dogmática jurídica permite a legitimação do poder no direito, garante o seu funcionamento, sempre irrestrito, com a ficção de um limite racional. Garante uma fantasia de segurança jurídica para um poder ambivalentemente limitado e irrestrito." (WARAT)

Primeiramente, cumpre ressaltar, que é a legitimação pela legalidade que marca o moderno poder penal resultante da intervenção do Direito (positivo = lei) na história do poder de punir. Segundo Baratta (1985) a forma de legitimação do poder, precisamente pela legalidade, mediante a qual o Estado moderno se faz e se apresenta como Estado de Direito e o seu poder de punir se afirma como direito (jus puniendi) de punir. Desta forma, a produção de uma ideologia legitimadora do poder penal, baseada no princípio da legalidade, acompanha desde o começo a história do direito penal.

Neste sentido, Resta (1986, p. 141) fala de um complexo processo de "autoreferência" que preside ao projeto jurídico moderno, "graças ao qual o Direito resolve por si mesmo o problema da legitimidade", pois é "a força da legalidade que demarca e determina cada mecanismo de legitimação": o "direito que fundamenta o poder de punir sobre a base de regras é o mesmo direito que fundamenta, em virtude de decisões, as regras fundadoras do direito de punir".

Entretanto, segundo Cancio Meliá (2005), "um dos debates mais intensos gerados por Jakobs com suas contribuições questiona se esse sistema é apenas um Direito Penal real ou, pelo contrário, é um sistema de Direto Penal legítimo".

E é exatamente na reconfiguração do direito penal que passa a crise da legitimidade no Estado Contemporâneo.

Para Andrade (1994) a legitimidade do sistema penal requer, desta forma, uma congruência da sua dimensão operacional em relação à sua dimensão programadora (normativa e teleológica) em nome da qual pretende justificá-lo; ou seja, requer não apenas sua operacionalização no marco da programação normativa (exercício racionalizado de poder), mas também o cumprimento dos fins socialmente úteis atribuídos ao Direito Penal e à pena (programação teleológica). Nesta perspectiva, "uma crise ou perda de legitimidade do sistema - que tem lugar na medida em que o sistema não opera no marco da programação ou não cumpre as funções declaradas - não é necessariamente acompanhada da perda de sua autolegitimação oficial" (Andrade, 1994, p. 301).

Além do mais, o campo penal, tradicionalmente um campo fechado, encontra-se hoje aberto e perturbado. Aberto pelo diálogo, que o impulso 
desestruturador passou a possibilitar, entre o penal e o social, o político e o econômico; e pela descoberta, que ele co-constituiu, de novos parceiros para o penal. Ao dialogar com as Ciências Sociais e abrir-se para uma nova roupagem, o penal deixa de ser, ao menos como experiência, monopólio analítico dos penalistas e monopólio da prática estatal. Até porque, a sociedade não é uma realidade que se possa conhecer objetivamente, mas o produto de uma "construção social" obtida mediante um processo de definição e de tipificação por parte dos indivíduos e grupos diversos. Conseqüentemente, o estudo da "realidade social" (por exemplo, a conduta desviada) significa, essencialmente, estudar esses processos, partindo do que é aplicado à simples comportamentos para chegar às construções mais complexas, como a própria ordem social (Baratta, 1991ª).

Deste modo, uma conduta não é criminal "em si" ou "per si" (qualidade negativa ou nocividade inerente) nem seu autor um criminoso por concretos traços de sua personalidade (patologia). O caráter criminal de uma conduta e a atribuição de criminoso a seu autor depende de certos processos sociais de "definição", que atribuem à mesma tal caráter de "seleção" que etiquetam um autor como delinqüente. Já para Becker (197, p. 14) "devemos reconhecer que não podemos saber se certo ato vai ser catalogado como desviante até que seja dada a resposta dos demais. $O$ desvio não é uma qualidade presente na conduta mesma, senão que surge da interação entre a pessoa que comete o ato e aqueles que reagem perante o mesmo".

Descreve Luhmann (1980), que a legitimidade é entendida como um processo, sendo obtida por uma série de interações, previamente estruturadas em subsistemas sociais. Essa predisposição à aceitação de decisões ainda indeterminadas que se denomina, modernamente, "legitimidade"; para diferenciar a sua concepção dinâmica, de legitimidade como processo ou ação legitimadora, da visão tradicional, Luhmann prefere o termo legitimação. Ademais, a legitimação é obtida ao longo de uma série de interações previamente estruturadas em subsistemas de comunicação específicos, chamados de os "procedimentos".

No entanto para Adeonato (2002) "o problema com essa normalização contrafática das expectativas a respeito de acontecimentos futuros, no exemplo do sistema jurídico, está em como obter dos destinatários das normas uma aceitação tácita de decisões que ainda não ocorreram e cujo conteúdo específico é - por conseguinte - indeterminado".

Porém, como todo sistema, o procedimento reduz a complexidade do mundo circundante selecionando determinadas alternativas de conduta em detrimento de outras que não são interiorizadas e que não podem ser argüidas, não importando em que medida tenha a ver com a realidade dos fatos. Desta maneira, a pessoa vê-se 
garantida pelo sistema e tem suas atitudes previamente "justificadas", ou seja, legitimadas. Em nível externo, por sua vez, o funcionamento adequado dos papéis assegura a autolegitimação do sistema contra eventuais contingências advindas de possibilidades não previstas (complexidade).

Por outro lado, se esses mecanismos procedimentais, não imunizam completamente o indivíduo de suas preferências individuais, pelo menos resguardam e aliviam sua carga pessoal e emocional. Assim, a proposição proposta deixa de ser a legitimação pela legalidade vinculada ao Direito Penal do fato e à segurança jurídica, - ou seja, a programação normativa do sistema penal, e passa a ser a legitimação pela utilidade vinculada ao Direito Penal do autor e à defesa social.

\section{- Do déficit ou subprodução de garantis mo e limites estruturais na racionalização da violência punitiva: da onipotência à ilusão de poder}

Entretanto, a complexidade desta espiral nos conduz a ir além. Pois, ao reconduzir seus déficits de garantismo ao seu déficit epistemológico cognoscitivo e concluir que o discurso dogmático é hoje mais do que nunca contestável como cognoscitivamente atrasado e empiricamente falsificado e que seu idealismo condiciona, até certo ponto, sua incapacidade estrutural para a racionalização garantidora, constata-se ao mesmo tempo em que o idealismo e a falsidade do discurso dogmático integram seu código ideológico (ideologia liberal + ideologia da defesa social) que tem sido fundamental à legitimação e à eficácia simbólica (reprodução ideológica) do sistema penal (ANDRADE, 1994).

Deste modo, verificamos que é precisamente por sobrepor à imagem real do sistema penal a uma imagem ideal do funcionamento do Direito Penal que o discurso dogmático tem tido uma eficácia simbólica legitimadora. Se toda a argumentação aqui desenvolvida demonstra que o limite do sistema penal é o limite da própria sociedade e, conseqüentemente, não pode ser atribuído unicamente a limitações dogmáticas; por outro lado é fundamental pontualizar tais limitações porque a Dogmática Penal assumiu a onipotente função de racionalizar o sistema. E, fazendoo, estaremos desvelando sua "ilusão" de poder neste sentido.

Assim, enquanto a Dogmática Penal centraliza a construção do sistema garantidor na conduta do autor edificando uma técnica de imputação de responsabilidade penal pautada por requisitos objetivos (conduta típica e antijurídica) e subjetivos (culpabilidade do agente imputável) e demarcando um horizonte decisório vinculado à legalidade e ao fato-crime cometido, em que a subjetividade do autor apenas ingressa como vontade (dolosa ou culposa) e culpabilidade em relação 
ao fato; são precisamente as variáveis relativas à pessoa do autor e outras, exorcizadas pela Dogmática pela porta da frente de sua construção conceitual que ingressam pela porta dos fundos e preponderam nas decisões judiciais.

O exercício de poder do sistema penal deixa a dogmática prisioneira da própria fantasia que cria definindo seus próprios limites e possibilidades; isto é, não apenas seus déficits, mas também seus excessos funcionais. Por sua vez, a própria funcionalidade dogmática não é controlada.

Todos estes argumentos concorrem para uma conclusão genérica fundamental: entre a evidência empírica de que o código tecnológico da dogmática tem sido utilizado para fundamentar juridicamente e justificar a legalidade, pois é em virtude mesmo da pré-programação legislativa e dogmática da ação jurisdicional que o sistema penal se legitima pela legalidade. Por isto, o discurso dogmático cai na onipotência, segundo Zaffaroni (1989, p. 135-6) "esta onipotência nos ensina até hoje que o discurso jurídico-penal deve legitimar o poder de todo o sistema penal para poder planificar o exercício de poder decisório da agência judicial nos poucos casos que as outras agências (executivas) selecionam para submetê-los a seu conhecimento. (...)".

Ao mesmo tempo em que a segurança jurídica aparece empiricamente falsificada, aparece simbolicamente reafirmada. De modo que "compramos a suposta segurança que o sistema penal nos vende, que é a empresa de mais notória insolvência estrutural de nossa civilização" (ZAFFARONI, 1991, p. 27).

Hoje está evidenciado que a apropriação dos potenciais garantidores da Dogmática Penal - que subsistem, todavia, no simbolismo de suas promessas - para uma ação rigorosamente correta da Justiça Penal somente pode se dar em situações contingentes e excepcionais. Mas não tem o poder de reverter à lógica da seletividade e a arbitrariedade do sistema.

É que, em definitivo, há uma distância abissal entre a abrangência e complexidade da fenomenologia do sistema penal revelada pela Ciência social e a apreensão reducionista e idealizada que dela faz a Dogmática Penal. O problema, portanto, "não está na tentativa de racionalização do "ser" (operacionalização) a partir do "dever-ser" (programação), mas nos pressupostos idealizados em que esta tentativa se apóia que, embora a converta numa tentativa análoga à do legendário "Sísifo", convive com uma onipotência e uma ilusão racionalizadora'.

\section{7 - ALGUMAS REFLEXÕES}


Ao seu turno, Roxin critica a concepção de Jakobs, afirmando que com o seu significado de restituir a identidade da sociedade, tem como conseqüência à perda do poder limitativo da mesma. Roxin (2006), também adverte acerca de um sistema social, a seu ver, "que não deve ser mantido por ser um valor em si mesmo, mas atendendo aos homens que vivem na sociedade do momento".

Ao final, Roxin (2006) reconhece que a tese de Jakobs aproxima-se perfeitamente da concepção defendida também por ele, quando recomenda a renuncia a normas "sem vigor". Ademais, o doutrinador reconhece que algumas das disposições penais de entrada não possuem uma função legitima, considerando que 'uma desautorização da norma como algo puramente interno deve ser irrelevante'.

Silva Sánchez (1992), por sua vez, elenca algumas críticas, afirmado que este método é passível de determinar um critério cientifico reduzido o que pode levar a dogmática a uma reconstrução arbitrária, contrária ás garantias do Estado Democrático de Direito.

Faticamente, desponta preocupante para os doutrinadores, qual o modelo definido pela norma? "Jakobs define como modelo funcional de determinado sistema social (identidade social). Então, o jurista tem que conhecer e identificar o indivíduo em seu contexto social e não apenas na sua subjetividade" (Breier, 2003, p. 98).

A fora estás questões, conclui Baratta que dois dos

(...) baluartes erguidos pelo pensamento penal liberal para limitar a atividade punitiva do Estado frente ao indivíduo: o princípio do delito como lesão de bens jurídicos e o princípio de culpabilidade, parecem cair definitivamente e são substituídos por elementos de uma teoria sistêmica, na qual o indivíduo deixa de ser o centro e o fim da sociedade e do direito, para se converter num 'subsistema físico-psíquico' (G. Jakobs), ao qual o direito valoriza na medida em que desempenhe um papel funcional em relação com a totalidade do sistema social (BARATTA, 1992, p. 71).

É visível, pois, que a teoria de Jakobs rompe o pacto dogmático com a segurança jurídica convertendo-a em exigência explícita de estabilização e segurança para o próprio sistema penal e social. E em nome de uma abertura da Dogmática Penal para a realidade ela opera o trânsito de uma ontologização (Welzel) para uma (re)funcionalização e uma (re)legitimação tecnocrática do sistema do delito. Desta maneira, a modernização da dogmática penal sobre o prisma sistêmico está intimamente relacionada com a "reação punitiva como função de restabelecer a 
confiança e reparar ou prevenir os efeitos negativos que a violação da norma produz para a estabilidade do sistema e integração social" (BARATTA, 1991ª , p 535).

Complementa Bolzan (1998, p. 93) que "a estabilidade jurídica, campo de estabelecimento de normas convivais, não pode significar o aprisionamento, o congelamento, de uma vez por todas, de seu conteúdo". Assim, "a alteração, mudança, renovação constantes não significam o caos. Ao contrario, conduzem ao engajamento, à identificação, mas nunca à uniformização”.

Bolzan (1998) citando Guattari disserta "é perfeitamente concebível que um outro tipo de singularidade se organize, a qual preserve processos de singularidade na ordem do desejo, sem que isso implique uma conformação total na escala da produção e da sociedade, sem que isso implique uma violência generalizada e uma incapacidade de humanidade fazer gestão da vida”.

Mesmo que criticado, a obra científica de Jakobs prima por sua originalidade em muitos aspectos, o que sem dúvida está atualmente proporcionando inúmeros debates científicos não só em nível de Alemanha como também internacionalmente. A pretensão de Jakobs em renormatizar o sistema penal oferece um novo panorama nos valores que há muito tempo estão intitulados no Direito penal: o repensar do que está edificado.

Afora estas questões, cumpre destacar que se trata de um problema metodológico. Apenas se está discutido acerca de em que medida se integra a atividade de analise crítica dentro do conjunto da ciência de Direito penal, e particularmente, em relação à dogmática. Ao contrário do que pode parecer, não existe determinadas opções teóricas que garantem melhores resultados políticocriminais ou uma determinada orientação política "perfeita".

\section{8 - CONSIDERAÇÕES FINAIS}

Nesse contexto, o presente artigo busca estimulando junto aos operadores do Direito um questionamento acerca da eficácia do método racional final utilizado até então, bem como provocar uma reflexão para uma nova proposta de Sistema Jurídico Penal, sendo, todo estudo amparado sob uma perspectiva sistêmica e complexa da proposta suscitada.

Porém, temos a consciência que em Direito, jamais poderemos alimentar a utopia de construções dogmáticas definitivas. O Direito Penal é um instrumento de força e de intervenção do Estado na sociedade marcado pela máxima coerção. Em sendo a sociedade dinâmica, inserida em um processo de contínua mutação dos valores sociais e culturais, é natural que o Direito Penal também se amolde a um 
gabarito de constante evolução. Quando isso não ocorre ou se processa em uma velocidade insuficiente, geram-se tensões cujo acúmulo culmina com rupturas.

O ponto da mutação já se encontra, desta perspectiva, instaurado. Ele radica no aprofundamento e radicalização do caminho aberto pela parceria CriminologiaPenalismo crítico, cujo elo reside no desenvolvimento do aspecto crítico da Criminologia ao encontro do aspecto garantidor do Direito Penal dogmático e viceversa; ou seja, no caminho de um garantismo crítico a curto e médio prazo inserido no horizonte utópico de superação do velho sistema de controle penal (ANDRADE, 1994).

Assim, a idéia de que o Direito Penal deve ser orientado a satisfazer as necessidades de uma nova sociedade, constituída em um sistema aberto a novas políticas criminais e de redes de complexidades. Portanto, há que se argumentar, uma vez que não há consenso sobre a matéria. E no momento em que falamos, fazemos uma oferta, como diria Habermas. E é o que estou fazendo a partir destas reflexões... Um convite ao diálogo. (STRECK, 2005).

Todavia, há uma questão lógica ainda não superada pela visão constitucional: a norma jurídica é apenas um dos elementos da formação do Direito, que não se esgota positivamente. Como bem preleciona o Professor Bolzan

Aqui e agora, importa desestabilizar, no âmbito do Jurídico, a utilização do direito como meio. Ou seja: a reorganização do Jurídico, dentro de um estilo democrático, baseado na incerteza, pressupõe que a regulamentação ou o mínimo coercitivo de regulamentação dos conflitos estejam baseados em estruturas de ação comunicativa dirigidas ao entendimento, pois somente a partir de um modelo de normatização, baseado no consenso obtido dialogicamente, é que se poderia pensar no estabelecimento de "instituições jurídicas" ao estilo habermasiano, as quais, somente assim, poderiam estabelecer vínculos com o mundo da vida. Apenas o direito como instituição teria possibilidade de vincular-se a um processo democrático que não se pretende estabelecido para sempre, sob a roupagem de um arcabouço jurídico formal e procedimentalmente legitimado nos moldes "previstos" pelo positivismo jurídico (Bolzan, 1998, p. 102).

A simples existência da contestação da norma posta por um sistema que se auto-organiza fora das instâncias formais, é suficiente para impelir ao questionamento da legitimidade desta norma. Isso não pode implicar, porém, 
imediatamente, em considerar essas representações como regras exigíveis de comportamento, porque não há consenso que as legitime.

Nota-se claramente do conceito e do objeto da Política Jurídica, que ela ocupa um espaço intermediário entre a norma e os anseios populares. Nesse sentido, impende vincar, como faz Gilberto Callado de Oliveira, o seguinte:

... a política jurídica está sempre numa posição além do direito positivo, orientandoo para as necessárias inserções e reformas. Penetra nele a princípio, com uma postura ética crítica, para a partir daí observar as tendências indesejáveis e contrárias aos interesses da coletividade e de sua própria razão de existir, e propor as mudanças de rumo, quer mediante correções adequadas, quer mediante a introdução de uma nova estrutura legal. São correções e acrescimentos inspirados pela conveniência e utilidade dos meios, tendo em vista o cotidiano progresso da sociedade, e a contínua transformação do direito, como o elevado objetivo de ajusta-los a uma verdadeira ordem social (p. 46).

Ao final, sua atuação estará intimamente ligada a uma maneira de realizar justiça (inclusive social) sem o abandono dos critérios de segurança jurídica.

Com esta realização, a Política do Direito estará sempre preconizando a aplicação da norma mais justa para o caso concreto, sem perder de vista a necessidade de manutenção do equilíbrio sistemático do Direito.

A esse respeito, Bolzan (1998, p. 114) leciona que "uma característica intrinsecamente relevante que é esse seu caráter de compromisso não com uma estrutura pré-concebida, mas com os seus próprios participantes e com o mundo que (n)os rodeia". E complementa isto não é uma utopia anárquica. É, simplesmente, a recolocação em pauta da possibilidade de se repensar o projeto civilizatório como um todo, de se rever à crise da civilização, a partir da possibilitação de recolocar a questão de "saber se não há outra maneira de ver e praticar as coisas, se não há meios de fabricar outras realidades, outros referencias...".

A reivindicação de sua redução e abandono convive com a de sua expansão. E se aquela primeira se faz acompanhar de um fortalecimento das garantias inexistentes, esta preconiza o próprio abandono de seu reconhecimento formal. Enquanto está demonstrada a debilidade dos potenciais garantidores do Direito Penal, continua se apostando neles.

Em fim, chegamos a uma conclusão: a lei garante o funcionamento democrático de uma sociedade. A inexistência da lei como ficção de plenitude significativa, igualmente leva a um uso totalitário do direito. O que resta saber: 
como se garante o funcionamento racional dessa margem de indeterminações? A resposta mais sincera, segundo Warat (2004), é através da dogmática jurídica.

Não obstante a diversidade de alternativas, para Jakobs a evolução é irreversível. Quem sabe, num futuro próximo - "mas tendo a consciência de que não é possível determinar qual será o resultado, pois a transformação social ocorre sem teleologia nem garantia, e é esta indeterminação que faz o futuro ser futuro" (BOAVENTURA, 1999, p. 270) - está proposta inovadora deixe de nos causar vertigens e mal-estares, e aprendamos a conviver paradoxalmente com as construções da realidade, tais como: incertas, complexidades, imprevisibilidade e a intersubjetividade.

A partir do acima exposto, percebemos que, "a nova teoria dos sistemas pode ser, então, uma saída que nos aponta o beco-sem-saída das nossas pretensões cognoscentes. E o direito, como a ordem normativa por excelência da sociedade é uma dentre as diversas formas que temos de descrever e, portanto, distinguir, nossas descrições de mundo" (QUEIROZ, 2003, p. 90).

Assim, a possibilidade de que no desdobramento desta crise se realize uma transformação da Dogmática Penal e da sua relação funcional com o sistema penal tendente a compensar sua deficiência e a interagir com o próprio sistema depende do deslocamento de sua separação à sua aproximação e abertura cognoscitiva para a realidade social; de seu monólogo e isolamento acadêmico à busca do diálogo interdisciplinar; da reprodução à autocrítica e suspensão do dogmatismo na Ciência Penal e da dogmatização à problematização de suas próprias premissas.

\section{9 - REFERÊNCIAS BIBILOGRÁFICAS}

ADEODATO, João Maurício. Ética e Retórica: para uma teoria da dogmática jurídica. São Paulo: Saraiva 2002.

ANDRADE. Vera Regina Pereira de. Dogmática e Sistema Penal: Em Busca da Segurança Jurídica Prometida. In: TESE Apresentada ao Curso de Pós-Graduação Em Direito da Universidade Federal de Santa Catarina. Florianópolis, 1994.

BREIER, Ricardo. Tendências atuais da ciência penal: breves apontamentos. In: Revista Ibero-Americana de Ciências Criminais. Porto Alegre: ESPM, Ano 4, número 9, maio/agosto, 2003. 
BARATTA, Alessandro. Integración-prevención: una "nueva" fundamentación de la pena dentro del teoria sistémica. Doctrina Penal, Buenos Aires, n.29, p.3-26 ene./mar. 1985.

.Criminologia crítica y crítica del Derecho penal: introducción a la Sociologia jurídico-penal. Tradução por Alvaro Bunster. México: Siglo veintiuno, 1991a.

BECKER, H. Los extraños. Buenos Aires: Tiempo Contemporáneo, 1971.

CALLEGARI, André Luiz. LYNETT, Eduardo Montealege. GUNTHER, Jakobs. MELEÁ, Manuel Cancio. Direito Penal e o Funcionalismo. Porto Alegre: Livraria do Advogado, 2005.

JAKOBS, Günther. Sociedade, Norma e Pessoa. Tradução de Mauricio Antonio Ribeiro Lopes. Barueri, São Paulo: Manole, 2003-A.

Ciência do Direito e ciência do Direto Penal. Tradução de Mauricio Antonio Ribeiro Lopes Barueri, São Paulo: Manole, 2003-B.

Fundamentos de Direito Penal. Tradução de André Luís Callegari. São Paulo: Revista dos Tribunais, 2003-C.

MORAIS, José Luis Bolzan de. A Subjetividade do Tempo: Uma perspectiva transdisciplinar do Direito e da Democracia. Poro Alegre: Livraria do Advogado, 1998.

LUHMANN, Nikolas. Sociologia do Direito I. Trad. Gustavo Bayer. Rio de Janeiro: Tempo Brasileiro, 1983.

Legitimação pelo procediment. Brasília: Ed. Unb, 1980.

QUEIROZ, Marisse Costa de. O Direito como Sistema Autopoiético: Contribuições para sociologia jurídica. In: Sequiência 46. Revista do Curso de Pós-graduação em Direito da UFSC. Ano XXIV - Julho de 2003. 
MELIÁ, Manoel Cancio. Um Novo Sistema de direito Penal. Considerações sobre a teoria de Günther Jakobs. Barueri, São Paulo: Manole, 2003.

OLIVEIRA, Gilberto Callado de. Política jurídica no ocidente: a crise das positividades internacional e nacional. Fiscolex, 2007.

RESTA, Eligio. La desmesura de los sistemas penales. Poder y Control Barcelona, n.0, p.137-147, 1986.

ROXIN, Claus. A proteção de bens jurídicos como função do Direito Penal. Tradução André Luis Callegari e Nereu José Giacomolli. Porto Alegre: Livraria do Advogado, 2006.

SANTOS, Boaventura de Souza. Pela Mão de Alice: O social e o político na pós-

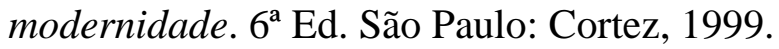

SILVA SÁNCHEZ, Jesús Maria. Aproximación al Derecho penal contemporâneo. Barcelona: Bosch, 1992.

STRECK, Lênio Luiz. A Concepção Cênica da Sala de Audiência e o Problema dos Paradoxos. Disponível em www.leniostreck.com.br. Acessado em: 28 de julho de 2005.

WARAT, Luis Alberto. Por Quem Cantam as Sereias. Informe sobre Ecocidadania, Gênero e Direito. In: Territórios Desconhecidos: A procura surrealista pelos lugares do abandono do sentimento e da reconstrução da subjetividade. Florianópolis: Fundação Boiteux, 2004.

ZAFFARONI, Eugenio Raúl. La crítica al Derecho Penal y el porvenir de la Dogmática Jurídica. In: CUESTA, Jose Luis de la et. al. (Comp.). Criminologia y Derecho Penal ao servicio de la persona. Libro-Homenage al profesor Antonio Berinstain. San Sebastián: Instituto Vasco de Criminologia, 1989.

Em busca das penas perdidas: a perda de legitimidade do sistema penal. Tradução por Vânia Romano Pedrosa e Amir Lopez da Conceição. Rio de Janeiro: Revan, 1991. 